\title{
Comparative Study of Bypass-Current MIG Welded-Brazed Aluminum/Galvanized Steel and Aluminum/Stainless Steel
}

\author{
Yu-Gang Miao ${ }^{1} \cdot$ Guang-Yu Chen $^{1} \cdot$ Peng Zhang ${ }^{1} \cdot$ Duan-Feng Han ${ }^{1}$
}

Received: 14 November 2016/Revised: 8 January 2017/Published online: 24 April 2017

(C) The Chinese Society for Metals and Springer-Verlag Berlin Heidelberg 2017

\begin{abstract}
A bypass-current metal inert-gas welding-brazing technology has been developed to join aluminum/galvanized steel and aluminum/stainless steel. Microstructure, intermetallic compounds and hardness distribution of the joints were studied by optical microscopy, scanning electron microscopy, energy-dispersive spectroscopy, X-ray diffraction analysis and microhardness tests. Comparative study on both types of joints was carried out. During aluminum to galvanized steel assembling, finer seam was obtained under a more stable process. A uniform interfacial reaction layer with a thickness of 2-4 $\mu \mathrm{m}$ was formed. During aluminum to stainless steel assembling, an uneven interfacial reaction layer with a thickness of 5-45 $\mu \mathrm{m}$ was formed. Intermetallic compounds at the interface of aluminum/galvanized steel were identified as $\mathrm{Fe}-\mathrm{Al}-$ $\mathrm{Si}-\mathrm{Zn}$ complex phases, while $\mathrm{Fe}-\mathrm{Al}-\mathrm{Cr}-\mathrm{Ni}$ complex phases were found at the aluminum/stainless steel interface. Microhardness of interfacial layer increases rapidly within reaction layer due to possible brittle intermetallic compounds.
\end{abstract}

KEY WORDS: Aluminum alloy; Steel; Intermetallic compounds; Dissimilar joining

\section{Introduction}

To reduce fuel consumption and greenhouse gas emission, the demand for weight reduction increases continuously in automotive and aerospace industries. Because of the advantages of low density, high specific strength and corrosion resistance, aluminum alloy has an increasingly wider range of application. It is attractive to make car bodies lighter by introducing some aluminum parts to replace steel structures. In view of the intersection application of aluminum and steel, it is essential to form a composite aluminum/steel structure, which can reduce the weight of the structure while maintaining the reliable

Available online at http://link.springer.com/journal/40195.

Duan-Feng Han

moideas@hrbeu.edu.cn

1 National Key Laboratory of Science and Technology on Underwater Vehicle, Harbin Engineering University, Harbin 150001, China strength. Therefore, it is of great significance to achieve reliable joint of aluminum alloy and steel.

The main issue associated with the joining of aluminum to steel is the nearly zero solid solubility of iron in aluminum, which results in the formation of brittle intermetallic compounds (IMCs) such as $\mathrm{FeAl}_{3}$ and $\mathrm{Fe}_{2} \mathrm{Al}_{5}$ that can severely impair the performance of composite structure. In addition, differences in thermal physical properties between aluminum and steel, such as melting temperature, expansion coefficient and thermal conductivity, might lead to greater residual stress during welding. Until today, steel and aluminum were mostly joined by mechanical means like screwing, riveting and clinching, and also by solidstate welding processes like explosion welding and friction welding. Despite the difficulties of assembling steel to aluminum by liquid-state processes, several studies have been carried out using conventional welding processes such as arc welding [1, 2], laser welding [3, 4], resistance spot welding [5, 6], brazing [7] or friction stir welding (FSW) $[8,9]$. Meco et al. [10] reported the application of laser in seam welding of dissimilar steel to aluminum joints. 
Fronius Company invented a CMT (cold metal transfer process) method. This method can be used to assemble aluminum to steel structure [11]. The principal innovation of this method is that the motions of the welding wire have been integrated into the welding process and into the overall control of the process [12].

Many studies have shown that the essential factor to obtaining a successful joint of aluminum and steel is the thickness of potential brittle IMC layer. Kreimeyer and Sepold [13] have found that, when joining aluminum to steel, sound joints could be achieved with IMC layer thickness of less than $10 \mu \mathrm{m}$. In addition, the authors also deemed that zinc coating can increase the wettability of the molten aluminum on steel surface. Murakami et al. [14] and Mathieu et al. [15] both pointed out that the welding temperature probably determined the thickness of the IMC layer and recommended the use of lower heat input methods to obtain a sound joint.

In order to achieve lower heat input with finer arc stability, more stable droplet transfer and relatively lower cost, experiments using bypass-current metal inert-gas (BC-MIG) arc welding-brazing method to join aluminum to galvanized steel and stainless steel were designed. In this method, a tungsten arc welding torch was set up as bypasscurrent circuit, and metal inert-gas (MIG) welding torch was set up as main current circuit. During the welding process, the welding current that passes through MIG torch was divided. Part of the main current goes through the base metal, while the other part goes through the tungsten torch as bypass current. As a result, welding current that passes through the base metal was reduced. With the application of this method, heat input of the base metal can be efficiently controlled to restrain the formation of brittle IMCs. Also, performance of the electromagnetic force that affects the droplet transfer and molten pool can be improved.

\section{Experimental Procedure}

Experiments of bypass-current MIG arc brazing-welding process were carried out to join 6061 aluminum alloy to Q235 galvanized steel using ER4043 aluminum alloy as filler metal, and to join 6061 aluminum alloy to SUS304 stainless steel using ER5356 aluminum alloy as filler metal. After that, both assemblies were analyzed by metallurgical and mechanical means, focusing on interfacial IMC layer. Microhardness test was executed to evaluate the mechanical characteristics of the joints. Macrostructure and microstructure of the joints were observed by optical microscopy $(\mathrm{OM})$ and X-ray diffraction (XRD). Interface characteristics and element distributions were analyzed by using a scanning electron microscope (SEM) equipped with an energy-dispersive spectroscopy (EDS).
All the aluminum and steel sheets were cut into rectangular strips of $200 \mathrm{~mm} \times 50 \mathrm{~mm}$ with thicknesses of $2 \mathrm{~mm}$. Q235 sheets with an approximately $15-\mu \mathrm{m}$ zinccoating layer were obtained using hot-dip galvanizing. ER4043 aluminum alloy was used as filler material with a dimension of $1.2 \mathrm{~mm}$ to join 6061 aluminum alloy and galvanized steel, which contains approximately 4.6-6.1\% of silicon. ER5356 aluminum alloy was used as filler material with dimension of $1.2 \mathrm{~mm}$ to join 6061 aluminum alloy SUS304 stainless steel. The chemical compositions of the materials are listed in Table 1.

In order to remove oxides and other contaminants that might impede the direct contact between the dissimilar materials, the surfaces of the aluminum and stainless steel sheets were polished with grade $800 \mathrm{SiC}$ paper and degreased with acetone. Galvanized steel sheets were only degreased due to zinc coating.

Assembling processes were under the protection of argon shielding gas flow. Aluminum alloy was assembled, respectively, to galvanized steel and stainless steel in lap configuration in which aluminum alloy sheet was set up on the top of the steel sheet. Electric arc was then striking on the aluminum sheet. The torches were pointed directly to the edge of the aluminum sheet. Both of the assemblies involve a liquid aluminum/solid-state steel interaction which leads to the formation of intermetallic layer. It is reported [16-18] that when a liquid steel/liquid aluminum interaction occurs, the aluminum fusion zone would crack because of the rapid formation and growth of intermetallic. For these reasons, a liquid steel/liquid aluminum interaction must be avoided.

The schematic diagram of bypass-current MIG weldingbrazing experimental setup is presented in Fig. 1. In the welding process, the BC-MIG welding setup was fixed with a tungsten welding torch ahead of a metal inert-gas (MIG) welding torch along the welding direction. MIG torch was set in vertical direction, and tungsten torch was set at an angle of approximately $30^{\circ}-60^{\circ}$. Current that goes through MIG torch is divided into two parts. One goes to base metal and the other goes through tungsten torch as bypass current. Furthermore, an IGBT controlling system is applied to optimize the value of bypass current. In this way, heat input of the base metal can be significantly deduced. Dilution rate of base metal can be limited. Also, projected transfer can be achieved in low current mode. The welding process is stable. Reliable joint with fine weld can be obtained.

Before the experiment, some preliminary trials had been made to find a set of optimized welding parameters. Parameters that were taken into consideration include: current of main circuit $I$, welding voltage $U$, current of bypass circuit $I_{\mathrm{p}}$, welding speed $V$, distance between base metal and tungsten $h_{1}$, distance between base metal and MIG torch $h_{2}$, distance between MIG torch and tungsten $d$, 
Table 1 Chemical compositions of base metal and filler metal (wt\%)

\begin{tabular}{|c|c|c|c|c|c|c|c|c|c|c|c|c|c|}
\hline Material & $\mathrm{Mg}$ & $\mathrm{Si}$ & $\mathrm{Mn}$ & $\mathrm{Cu}$ & $\mathrm{Zn}$ & $\mathrm{Ti}$ & $\mathrm{Cr}$ & $\mathrm{Ni}$ & $\mathrm{C}$ & $\mathrm{P}$ & S & $\mathrm{Al}$ & $\mathrm{Fe}$ \\
\hline $6061 \mathrm{Al}$ alloy & $0.8-1.2$ & $0.4-0.8$ & $\leq 0.15$ & $0.15-0.40$ & $\leq 0.25$ & $\leq 0.15$ & $\begin{array}{l}0.04- \\
0.35\end{array}$ & - & - & - & - & Bal. & $\leq 0.7$ \\
\hline $\begin{array}{l}\text { Galvanized } \\
\text { steel }\end{array}$ & - & $\leq 0.30$ & $0.30-0.65$ & - & - & - & - & - & $0.14-0.22$ & $\leq 0.045$ & $\leq 0.050$ & - & Bal. \\
\hline Stainless steel & - & $\leq 1.0$ & $\leq 2.0$ & - & - & - & $18-20$ & $8-10.5$ & $\leq 0.08$ & $\leq 0.035$ & $\leq 0.03$ & - & Bal. \\
\hline ER4043 filler & 0.05 & $4.6-6.1$ & 0.05 & 0.3 & 0.1 & 0.2 & - & - & - & - & - & Bal. & 0.8 \\
\hline ER5356 filler & 5 & 0.3 & 0.15 & 0.05 & 0.05 & 0.1 & 0.1 & - & - & - & - & Bal. & - \\
\hline
\end{tabular}

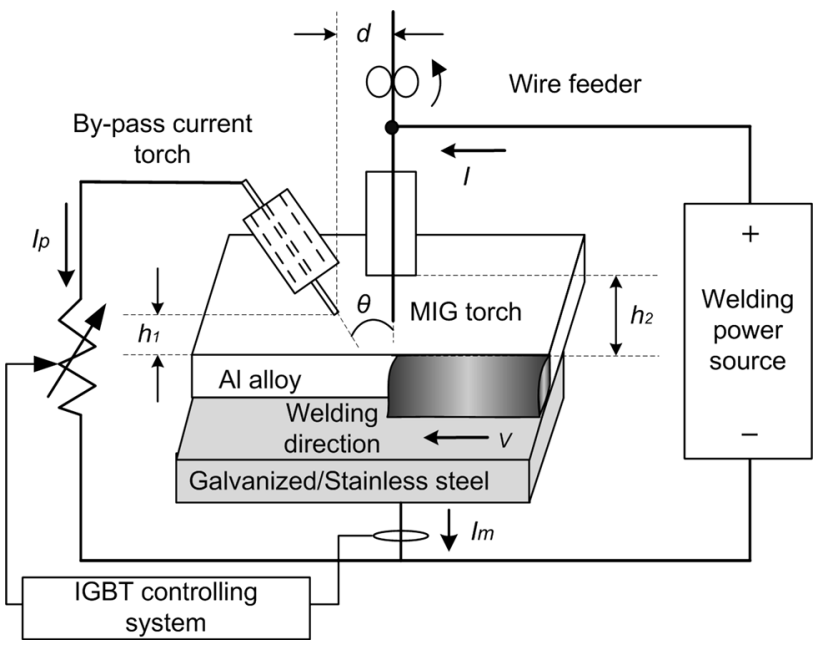

Fig. 1 Schematic diagram of bypass-current MIG welding-brazing experimental setup

MIG torch argon gas flow $q_{1}$ and bypass-current torch (BC) argon gas flow $q_{2}$. The optimized parameters are listed in Table 2.

After the welding, specimens with a typical cross section of the seam were cut, polished by $200,400,800$ and $1200 \mathrm{SiC}$ grades and then followed by a 2.5 - and $1-\mu \mathrm{m}$ diamond suspension to a mirror-like surface. After that, specimens were etched with Keller's reagent (1\% HF, $1.5 \%$ $\mathrm{HCl}, 2.5 \% \mathrm{HNO}_{3}, \mathrm{H}_{2} \mathrm{O}$ solution) to reveal the aluminum microstructure, $\mathrm{Nital}\left(4 \% \mathrm{HNO}_{3}\right.$ ethanol solution) to attack the galvanized steel structure and aqua regia (25\% concentrated $\mathrm{HNO}_{3}$ and $75 \%$ concentrated HCL mixture) to attack stainless steel structure. Then, microstructures of the joints were examined by optical microscopy (OM), scanning electron microscopy (SEM) with an energy-dispersive spectroscopy (EDS) and X-ray diffraction analysis (XRD). Microhardness (100-200 g loading force) was carried out on cross sections to further estimate the local mechanical properties of heat-affected zone (HAZ) and interfacial reaction layer (RL).

\section{Results and Discussion}

\subsection{Weld Appearance and Microstructure}

Figure 2 shows the appearances of aluminum to galvanized steel joint (Fig. 2a) and aluminum to stainless steel joint (Fig. 2b). The direct arc irradiation on the aluminum alloy sheet coupled with the lap configuration of both joints allowed the direct melting of aluminum and its wetting on the steel sheet. The joints were then obtained by liquid

Table 2 Welding parameters

\begin{tabular}{llc}
\hline Parameters & Al/galvanized steel & Al/stainless steel \\
\hline Welding current of main circuit, $I(\mathrm{~A})$ & 70 & 68 \\
MIG torch argon gas flow, $q_{1}\left(\mathrm{~L} \mathrm{~min}{ }^{-1}\right)$ & 15 & 15 \\
Bypass current, $I(\mathrm{~A})$ & 55 & 30 \\
BC torch argon gas flow, $q_{2}\left(\mathrm{~L} \mathrm{~min}^{-1}\right)$ & 5 & 5 \\
Welding voltage, $U(\mathrm{~V})$ & 16.6 & 16 \\
Welding speed, $v\left(\mathrm{~mm} \mathrm{~s}^{-1}\right)$ & 13.1 & 12 \\
Distance between base metal and tungsten, $h_{1}(\mathrm{~mm})$ & 5 & 5 \\
Distance between base metal and MIG torch, $h_{2}(\mathrm{~mm})$ & 12 & 10 \\
Distance between MIG torch and tungsten, $h_{3}(\mathrm{~mm})$ & 5 & 3 \\
\hline
\end{tabular}


(a)

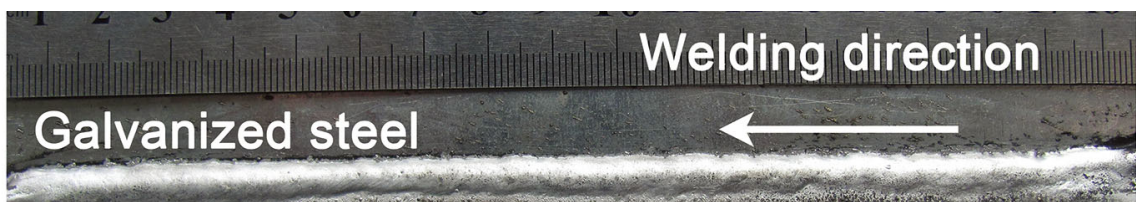

\section{Aluminum alloy}

(b)

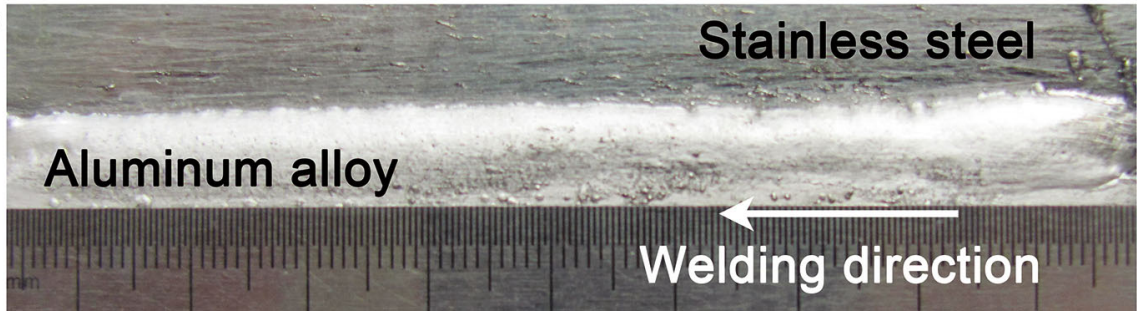

Fig. 2 Seam appearance of the joints obtained by BC-MIG: a aluminum/galvanized steel joint, $\mathbf{b}$ aluminum/stainless steel joint

aluminum/solid steel interaction, which lead to the formation of an intermetallic reaction layer (reactive wetting). Between these two morphologies of the seam, it can be inferred that process of aluminum alloy to galvanized steel welding is more stable and has fewer splashes compared to

(a)

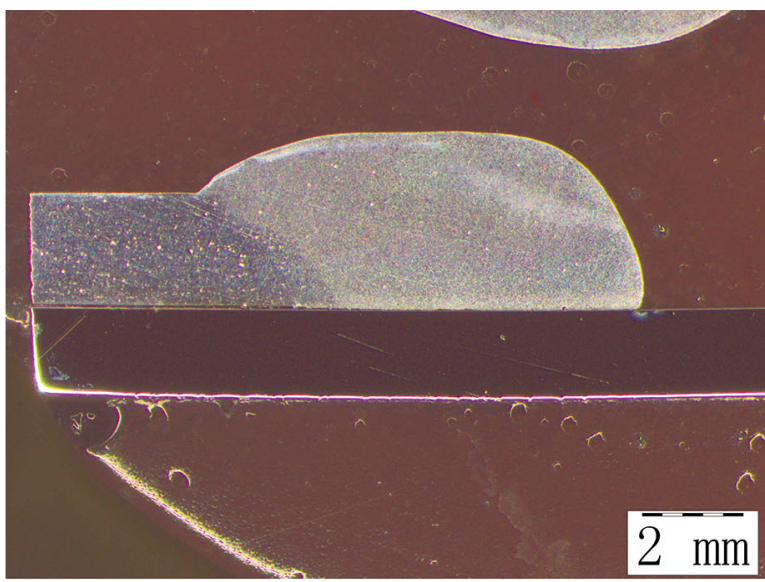

(b)

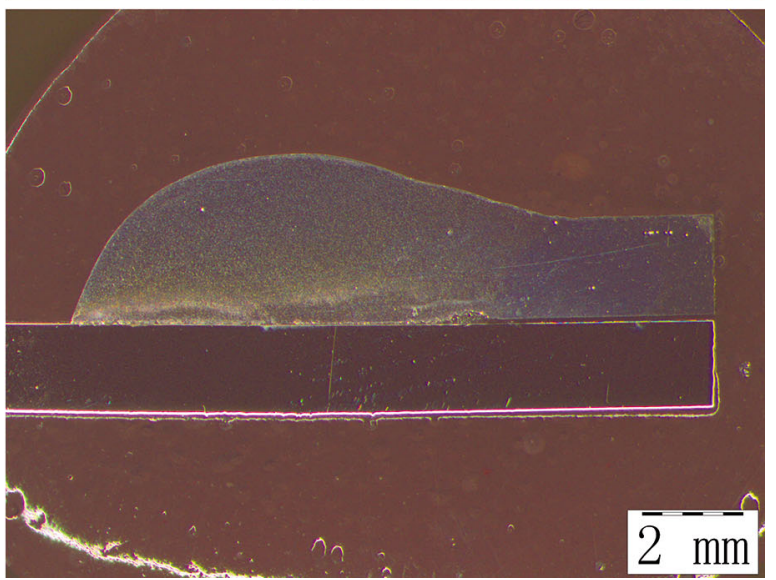

Fig. 3 Cross section of the joints obtained by BC-MIG: a aluminum/galvanized steel joint, $\mathbf{b}$ aluminum/stainless steel joint that of aluminum alloy to stainless steel welding. Cross sections of both of the joints are shown in Fig. 3.

Figure 4 shows the microstructures of the sections of aluminum/galvanized steel joint (Fig. 4a) and aluminum/ stainless steel joint (Fig. 4b). For aluminum/galvanized

(a)

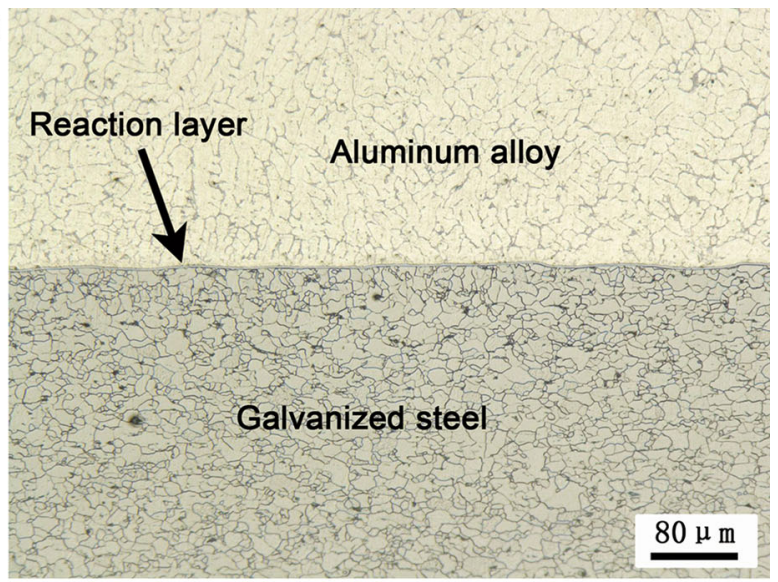

(b)

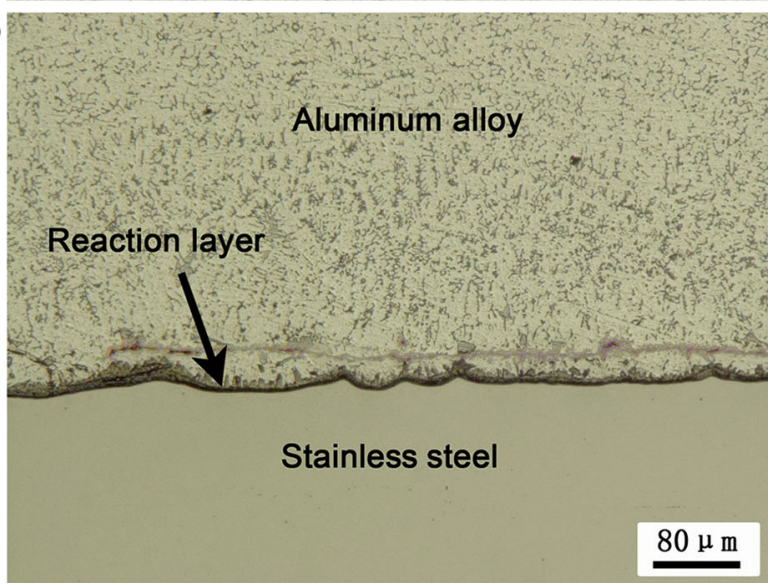

Fig. 4 Interface macrographics of the joints: a aluminum/galvanized steel joint, $\mathbf{b}$ aluminum/stainless steel joint 
steel assembly, although steel remained in solid state during reactive wetting process and no penetration of aluminum was found in steel matrix, severe microstructure refinement can be observed in the HAZ of the low-carbon steel. On the aluminum side, grain structure of the aluminum HAZ is slightly coarser than that of the aluminum base metal. However, due to a rather narrow range of HAZ, these changes of the microstructure are considered relatively small. For aluminum to stainless steel assembly, affection on the microstructure of the stainless steel is limited.

The interfacial reaction layers were formed during reactive wetting in both of the assembling processes. Thin and safe interfacial RL of aluminum/galvanized steel was formed with clear and even edges and a rather uniform thickness. However, geometry of the RL of aluminum/ stainless steel assembly is rather irregular compared to that of the aluminum/galvanized steel assembly, which had an uneven thickness and rough edges. Slightly unfused regions and fractures can be observed in the cross section of interfacial reaction layer and, noteworthily, partly melting of the steel can be observed in the interface geometry. It should be noticed that without zinc-coating layer, chemical compositions of these two kinds of steel base metal are rather different. Due to the melting of zinc, infiltration could not happen during aluminum to stainless steel assembling process. Similarly, chromium and nickel in the stainless steel could possibly have a major effect on the formation of reaction layer.

Coupled arc of tungsten and MIG torches was formed during the BC-MIG brazing-welding process as it is shown in Figs. 5 and 6. Current of the main welding circuit that went through MIG torch was divided by tungsten torch, and current that struck on the base metal was reduced. As shown in Fig. 5b, the upward rejection of droplet was a typical repelled transfer, which broadened the wetting and spreading area of the droplet. It can, therefore, be concluded that the bypass arc not only stabilized the MIG arc, but also extended the roof of the coupling arc. The droplet was completely surrounded and was forced to transfer in the direction of an electromagnetic force. In addition, plasma that flowed from the upper side to the bottom of the droplet was accelerated by the bypass arc, thereby facilitating the detachment of the droplet from the welding wire. The spot force generated by the coupled arc and the reacting force generated by the excessive evaporation of aluminum repelled the transfer of droplet and the diffusion time among the elements and thereby achieved the full melting and spreading of filler solder [19]. Meanwhile, the weld pool of the conventional MIG welding process was uneven with vigorous liquid metal motion and the surface is rough, which agrees with the observation in Fig. 6a. After the bypass current was applied, the arc shape (a)
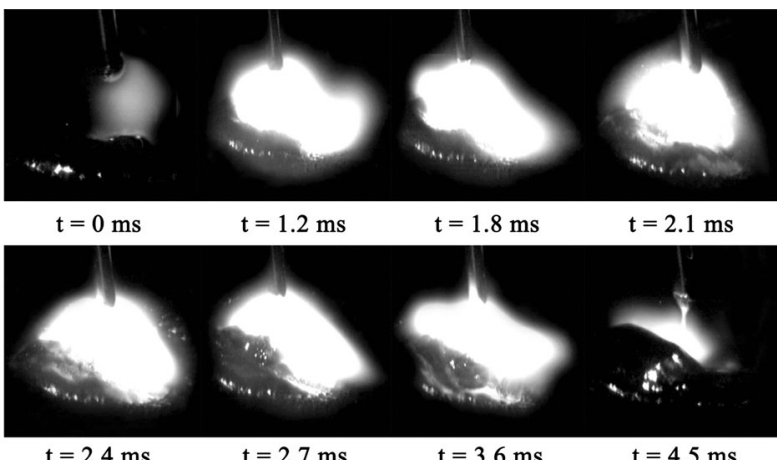

(b)

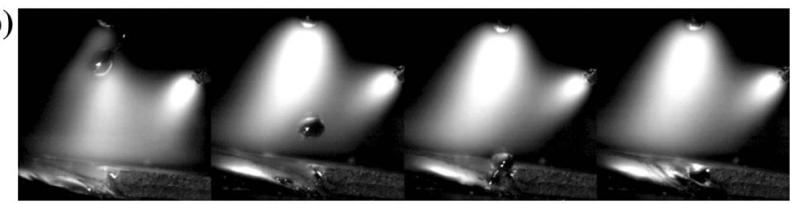

$\mathrm{t}=0 \mathrm{~ms}$

$\mathrm{t}=1.2 \mathrm{~ms}$

$\mathrm{t}=2.7 \mathrm{~ms}$

$\mathrm{t}=3.6 \mathrm{~ms}$

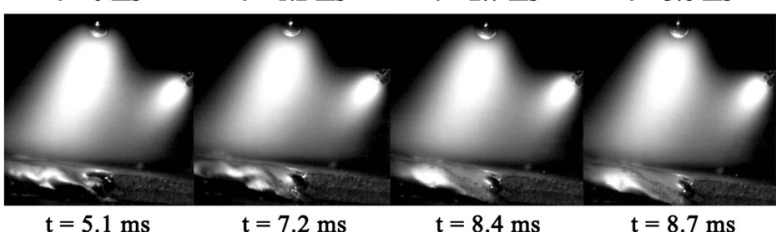

Fig. 5 Flow of weld pool and droplet transfer with and without bypass current: a conventional MIG, b BC-MIG
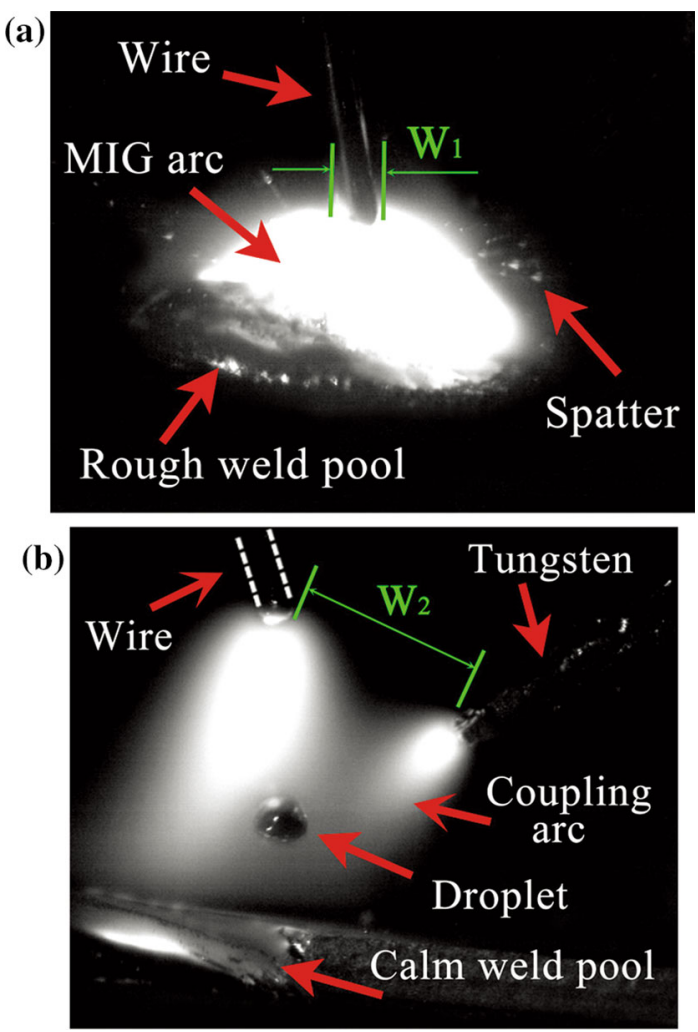

Fig. 6 Arc shape and appearance of weld pool with and without bypass current: a conventional MIG, b BC-MIG 
becomes more stable and the weld pool was calm, except when the droplet entered the weld pool and tiny ripples occurred on the surface (Fig. 6b) [20].

The stability of the arc produced by using BC-MIG method can also be evidenced by the variation of the currents as shown in Fig. 7. It can be seen that the current fluctuated markedly in the conventional MIG welding process. However, after the bypass current was added, both main circuit current and base metal current were significantly stabilized and became smoother. That suggests a more stable droplet transfer of the coupled arc in the BCMIG welding process, which agrees with the observation of arc stability from the high-speed video.

Valve of the bypass current is an essential factor in this BC-MIG welding-brazing assembling process. Excessive valve of the bypass current would lead to an insufficient melting, and consequently, formation of the seam would be adversely affected. By contrary, under a small valve of bypass current, coupling of the tungsten arc and MIG arc could not be achieved.

\subsection{Interface Analysis}

Figure 8a shows the SEM microstructure of the reaction layer of aluminum/galvanized steel assembly. Thin and safe RL with a thickness of approximately $2-4 \mu \mathrm{m}$ is exhibited, which proves that the heat input of the process was efficiently reduced. As a result, growth of the possible brittle IMC was restrained. It can be observed that the edge of the RL near steel side is rather smooth, while the edge near aluminum side shows a cellular/serration in shape. This indicates that RL grew from interface toward the galvanized steel side during the process.

EDS line scanning analysis of the interface shows that within the reaction layer, content of Fe decreases gradually from steel side to aluminum side. In contrast, aluminum

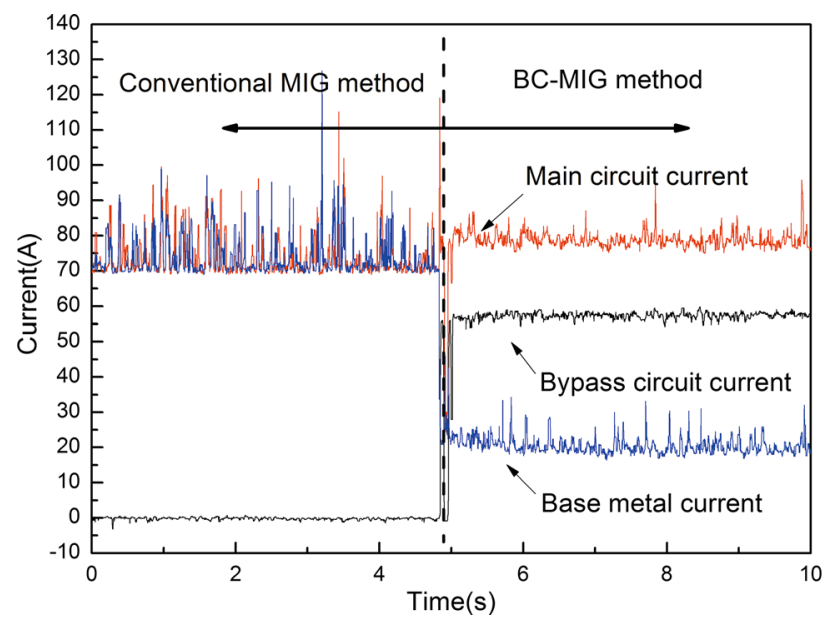

Fig. 7 Variation of currents with and without bypass current (a)
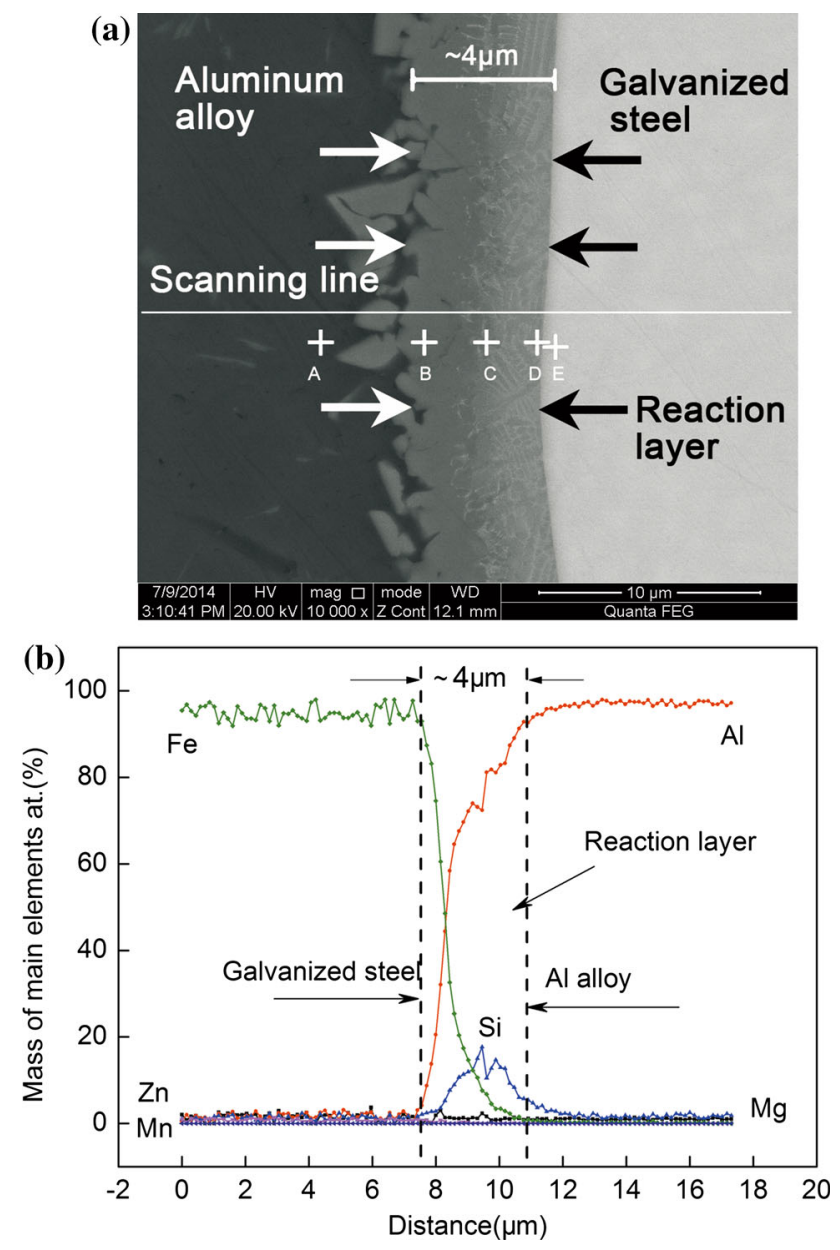

Fig. 8 a Microstructure b line scanning analysis results of the aluminum/galvanized steel interfacial layer

increases gradually along the same direction. EDS results (Table 3) of region D indicated in Fig. 8a show that ratio of $\mathrm{Fe}$ to $\mathrm{Al}$ is about 2:5 (at.), suggesting the formation of $\mathrm{Fe}_{2} \mathrm{Al}_{5}$. It is a typical composition of the RL in the case of solid-state to liquid aluminum interaction that a thin $\mathrm{FeAl}_{3}$ layer was formed on the aluminum side and a thicker $\mathrm{Fe}_{2} \mathrm{Al}_{5}$ layer was formed directed toward the steel side [21] due to the lower Gibbs free energy of these phases [22]. However, an enrichment of silicon that comes from the aluminum filler wire within RL (up to 17 at.\%) can be

Table 3 EDS results of the certain points indicated in Fig. 8a (at.\%)

\begin{tabular}{llrllll}
\hline Point & \multicolumn{7}{l}{ Aluminum/galvanized steel } \\
\cline { 2 - 7 } & $\mathrm{Al}$ & $\mathrm{Si}$ & $\mathrm{Mg}$ & $\mathrm{Mn}$ & $\mathrm{Fe}$ & $\mathrm{Zn}$ \\
\hline $\mathrm{A}$ & 96.33 & 2.22 & 1 & 0 & 0.45 & 0.67 \\
$\mathrm{~B}$ & 81.82 & 12.74 & 0.7 & 0 & 4.51 & 0.23 \\
$\mathrm{C}$ & 69.65 & 11.33 & 1.3 & 0.32 & 17.39 & 0 \\
$\mathrm{D}$ & 64.56 & 8.92 & 1.15 & 0 & 25.36 & 0.54 \\
$\mathrm{E}$ & 20.53 & 2.79 & 1.87 & 0.25 & 74.56 & 0 \\
\hline
\end{tabular}


observed, implying that part of silicon was also diffused into the interfacial layer, and therefore, Al-Fe-Si ternary phase was possibly formed.

Ratio of $\mathrm{Al}$ to the combination of $\mathrm{Fe}$ and $\mathrm{Si}$ is about $3: 1$ (at.) near aluminum side (region B indicated in Fig. 8a) and 5:2 (at.) near steel side (regions $\mathrm{C}$ and $\mathrm{D}$ indicated in Fig. 8a), suggesting that during reactive wetting, silicon atoms took the place of iron atoms and reacted with aluminum atoms. Formation of brittle $\mathrm{Al}-\mathrm{Fe}$ binary compounds was thereby restrained. Formation of $\mathrm{Al}_{7.4} \mathrm{Fe}_{2} \mathrm{Si}$ was detected by XRD (Fig. 9). Zinc coating of the galvanized steel sheet on the top of the seam was possibly molten and even evaporated (melting point of $\mathrm{Zn}$ is about $420{ }^{\circ} \mathrm{C}$; boiling temperature is about $906{ }^{\circ} \mathrm{C}$ ) [23]. Distribution of zinc is rather inconsistent along $\mathrm{RL}$ due to a temperature gradient of the arc. At the center of the arc, zinc coating was completely molten and evaporated due to a relatively higher temperature, leading to a rather low content of zinc, while at the edge of the arc, where the temperature is relatively lower, zinc coating was not completely molten. Also, the molten zinc that came from the center of the arc gathered in this region by the arc force, and an $\mathrm{Al} / \mathrm{Zn} \alpha$-solid solution region ( $\mathrm{Zn}$-rich zone) was formed. Peyre et al. [24] have reported that zinc coating allows better wetting and generation of intermetallic compounds. Previous studies showed the formation of $\eta$ $\mathrm{Fe}_{2} \mathrm{Al}_{5}, \tau-\mathrm{Al}_{7.4} \mathrm{Fe}_{2} \mathrm{Si}$ and $\tau_{6}-\mathrm{Al}_{4.5} \mathrm{FeSi}$ [25] or $\theta-\mathrm{FeAl}_{3}, \tau_{5^{-}}$ $\mathrm{Al}_{7.4} \mathrm{Fe}_{2} \mathrm{Si}$ and $\tau_{1-9}-\mathrm{Al}_{3} \mathrm{Fe}_{3} \mathrm{Si}_{2}$ [26] in the $\mathrm{Fe}-\mathrm{Al}-\mathrm{Si}$ and in the $\mathrm{Fe}-\mathrm{Al}-\mathrm{Si}-\mathrm{Zn}$ systems, respectively. This mechanism effectively avoided the formation of $\mathrm{Al}-\mathrm{Fe}$ brittle phase and therefore improved the mechanical properties of the joint.

Figure 10a shows the SEM microstructure of reaction layer of aluminum/stainless steel assembly. An uneven and

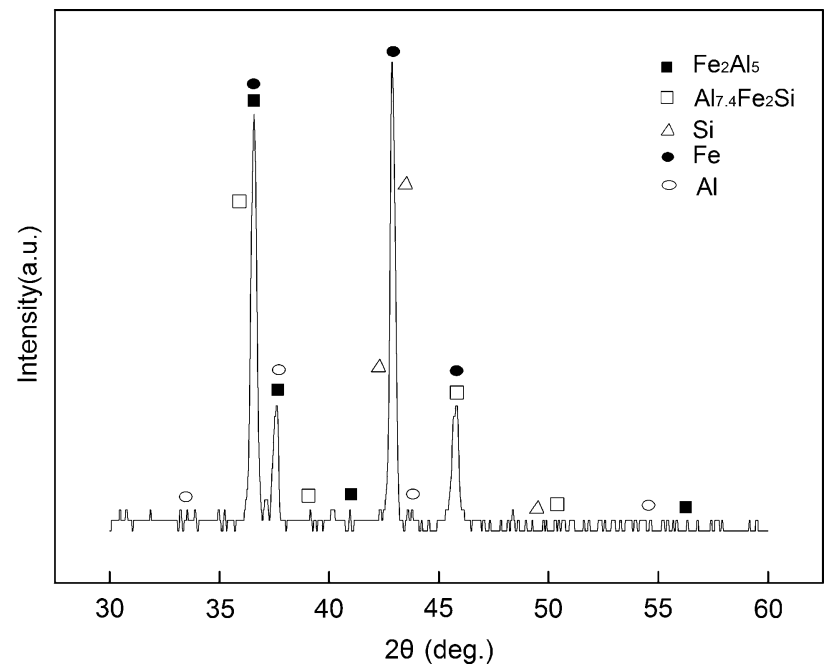

Fig. 9 XRD analysis result of aluminum/galvanized steel reaction layer discontinuous RL was formed during aluminum/stainless steel assembling process. Compared to the RL in aluminum/galvanized steel assembling, thickness of IMC region is rather discrepant, ranging from about 5-45 $\mu \mathrm{m}$.

Slight melt of the steel can be observed in the interfacial area. As it was mentioned in this paper, a rapid formation and growth of IMC were induced by the interaction of liquid steel/liquid aluminum in the regions where melting of the steel occurred, leading to a formation of thick RL. In other regions where melting of steel did not occurr, much fewer IMCs were formed during reactive wetting compared to aluminum/galvanized steel assembling. Consequently, thickness of RL within these regions is significantly thinner. The EDS analysis result (Table 4) shows that the ratio of $\mathrm{Al}$ to $\mathrm{Fe}$ is about 7:2 (at.) (Fig. 10b). It can be inferred that the IMC in the $\mathrm{RL}$ region is rich in $\mathrm{Al}$ phase. $\mathrm{FeAl}_{3}$ and $\mathrm{Fe}_{2} \mathrm{Al}_{5}$ are most easy to be formed due to the low Gibbs free energy. As a result, phases of the interfacial IMCs could possibly be $\mathrm{Fe}_{4} \mathrm{Al}_{13}, \mathrm{FeAl}_{3}$ and $\mathrm{Fe}_{2} \mathrm{Al}_{5}$, which is also reported in the previous studies [27, 28].

(a)
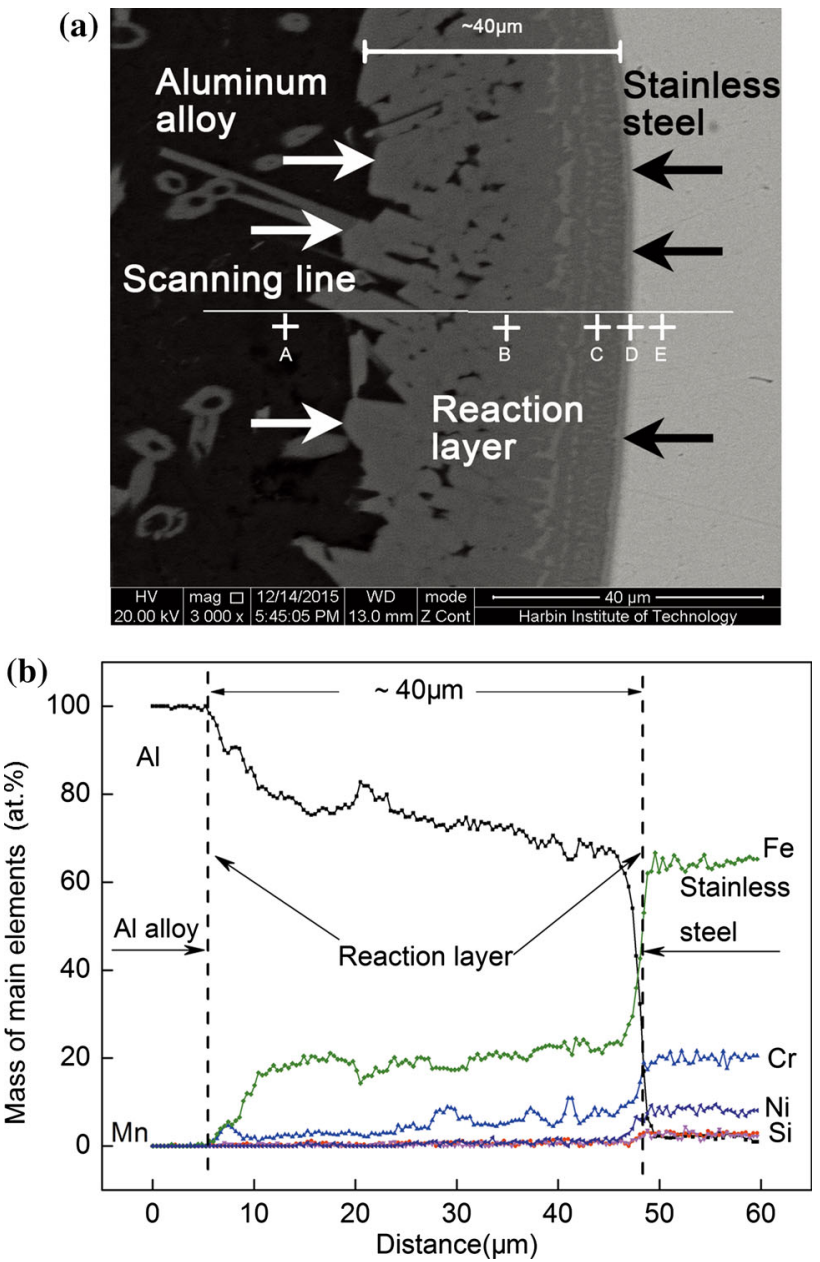

Fig. 10 a Microstructure b line scanning analysis results of the aluminum/stainless steel interfacial layer 
Table 4 EDS results of the certain points indicated in Fig. 10a

\begin{tabular}{lllllll}
\hline Point & \multicolumn{6}{l}{ Aluminum/stainless steel (at.\%) } \\
\cline { 2 - 7 } & $\mathrm{Al}$ & $\mathrm{Si}$ & $\mathrm{Cr}$ & $\mathrm{Mn}$ & $\mathrm{Fe}$ & $\mathrm{Ni}$ \\
\hline $\mathrm{A}$ & 100 & 0 & 0 & 0 & 0 & 0 \\
$\mathrm{~B}$ & 73.91 & 0.63 & 3.99 & 0.71 & 19.93 & 0.83 \\
$\mathrm{C}$ & 70.63 & 1.38 & 4.46 & 0.49 & 22.67 & 0.37 \\
$\mathrm{D}$ & 43.22 & 1.7 & 11.13 & 1.43 & 35.93 & 6.58 \\
$\mathrm{E}$ & 4.55 & 2.94 & 18.95 & 1.89 & 62.46 & 9.21 \\
\hline
\end{tabular}

During the welding process, molten aluminum spreads on the surface of stainless steel sheet containing chromium and nickel. With the participation of chromium and nickel, multiple metal compounds of $(\mathrm{Fe}, \mathrm{Cr}, \mathrm{Ni})_{4} \mathrm{Al}_{13}$, $(\mathrm{Fe}, \mathrm{Cr}, \mathrm{Ni}) \mathrm{Al}_{3}$ and $(\mathrm{Fe}, \mathrm{Cr}, \mathrm{Ni})_{2} \mathrm{Al}_{5}$, etc., were formed [29]. EDS results of different regions indicated in Fig. 10a are shown in Table 4. EDS shows that a certain amount of chromium and nickel exists in RL (regions B, C and D indicated in Fig. 10a). Content of nickel is lower than that of chromium, implying that nickel mainly exists in the form of solid solution compound. Chromium took the place of iron and a small amount of $\mathrm{Al}-\mathrm{Fe}(\mathrm{Cr}) \mathrm{IMC}$ was formed during the reactive wetting. Specifically, formations of $\mathrm{Al}_{76.8} \mathrm{Fe}_{24}, \mathrm{Al}_{4} \mathrm{CrNi}_{15}$ and $\mathrm{Al}_{13} \mathrm{Fe}_{4}$ were detected in XRD (Fig. 11), which further confirms the essential role of nickel and chromium in the formation of interfacial IMC. Silicon that existed in aluminum filler almost completely permeated into stainless steel base metal and therefore failed to form $\mathrm{Al}-\mathrm{Fe}-\mathrm{Si} \mathrm{IMC}$. As a result, more potential brittle IMC of $\mathrm{Al} / \mathrm{Fe}$ was formed in the aluminum/stainless steel RL. Due to the application of BC-MIG technique, heat input of the base metal was significantly reduced. Consequently, formation of potential brittle IMC region was effectively restrained; therefore, mechanical properties

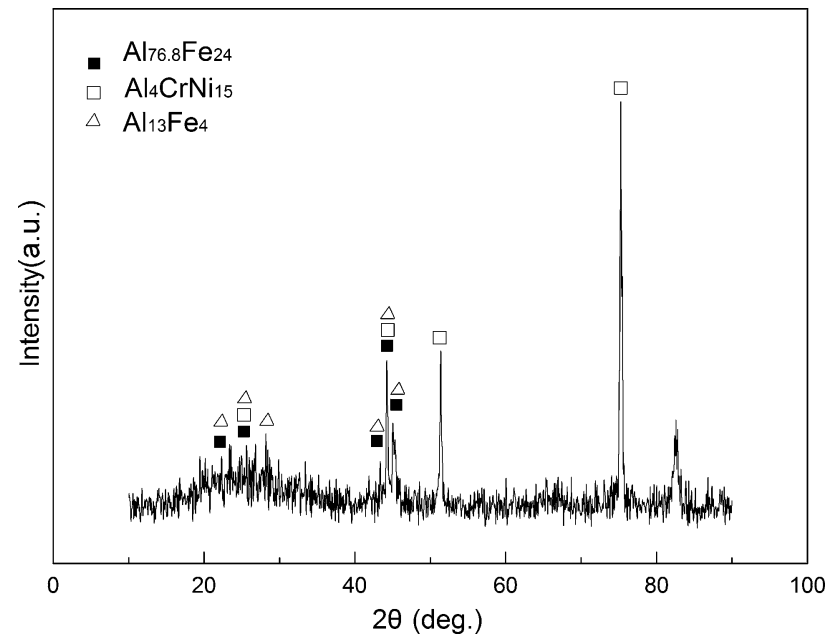

Fig. 11 XRD analysis result of aluminum/stainless steel reaction layer of aluminum/stainless steel assembly were improved. Comparing to aluminum/galvanized steel, molten aluminum spread on the surface of solid-state stainless steel with the presentation of chromium and nickel $[30,31]$ and formed IMC. In conclusion, chromium and nickel have essential effect on the formation of RL of aluminum/ stainless steel.

\subsection{Mechanical Properties}

Transverse tensile tests were carried out to evaluate their mechanical properties of both joints. Figure 12 shows the different failure locations of the specimens. As shown in Fig. 12a, failure of the aluminum to galvanized steel assemble occurred in the HAZ. The maximum strength of the specimen is $187.1 \mathrm{Mpa}$, which is slightly higher than aluminum alloy base metal (179.5 Mpa). This evidenced that reliable assembly of aluminum to galvanized steel was obtained after the process. On the contrary, failure of the aluminum to stainless steel assembly occurred at the RL region (Fig. 12b), which indicates that combination of two

(a)

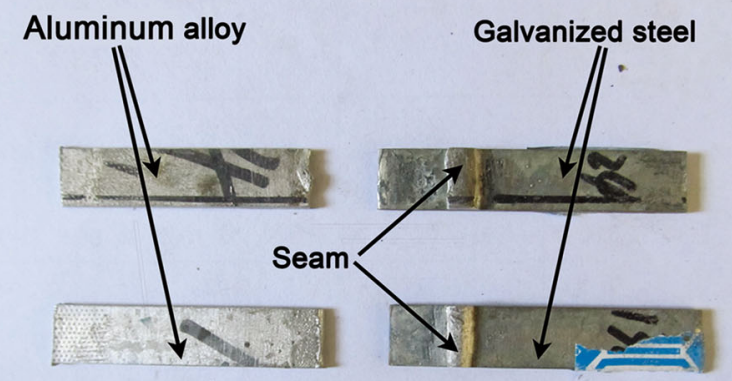

(b)

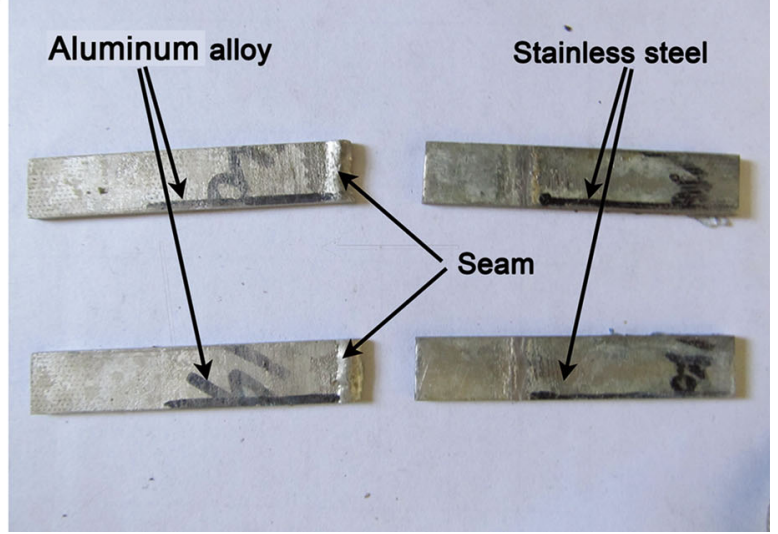

Fig. 12 Failure location of a aluminum/galvanized steel specimen, b aluminum/stainless steel specimen of the tensile strength testing 


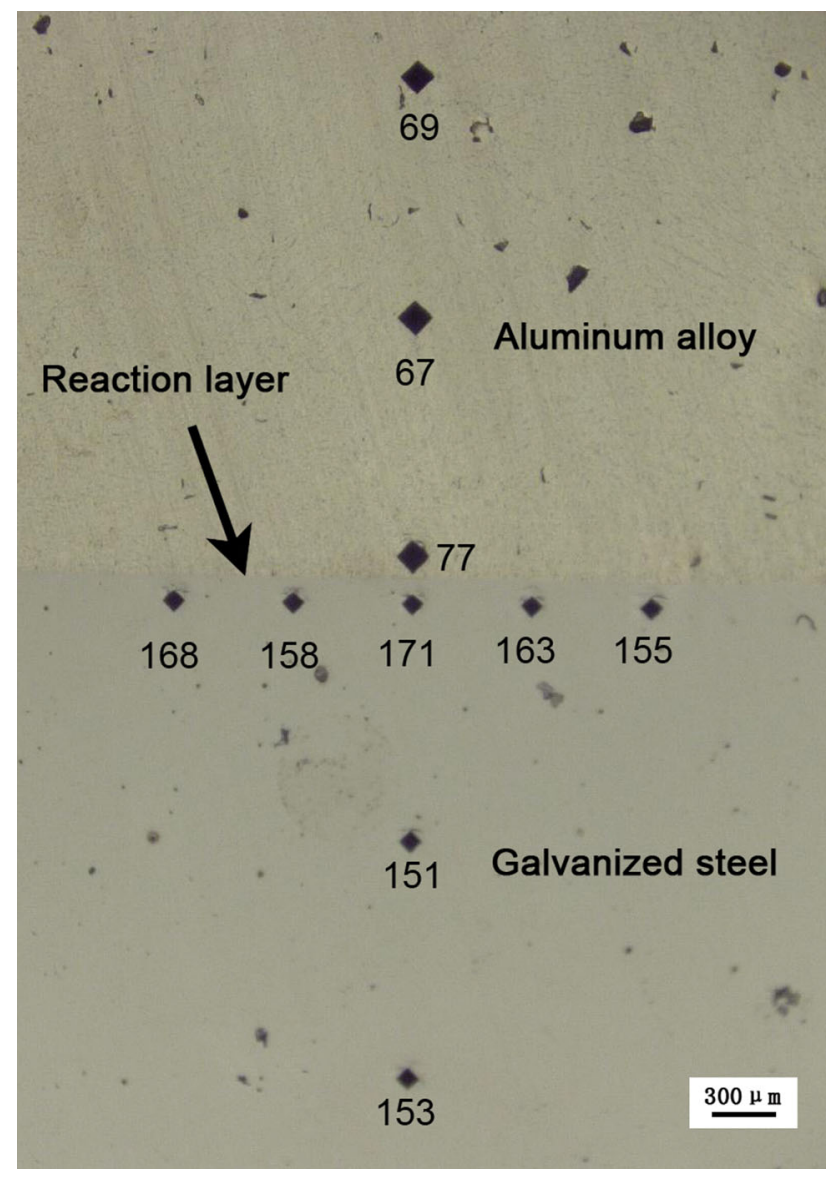

Fig. 13 Microhardness of the aluminum/galvanized steel joint (Hv)

materials is relatively weaker. Maximum strength of the aluminum to stainless steel is $99.1 \mathrm{Mpa}$.

The thickness of the RL is rather thin, so microhardnesses of the metal on and near the RL were both tested. Figure 13 shows the microhardnesses of some content points on base metal and near RL of the aluminum to galvanized steel joint. It can be observed that hardness near RL region (about $160 \mathrm{Hv}$ ) is obviously higher than that of the galvanized steel region (about $150 \mathrm{Hv}$ ). This might be due to the fact that elements of different metals mutually diffused into each other and led to alloying and solid solution strengthening of the base metals near RL. Brittle IMC was formed during the welding process and enhanced the hardness of the RL region as hardnesses of $\mathrm{Fe}_{4} \mathrm{Al}_{13}$, $\mathrm{FeAl}_{3}$ and $\mathrm{Fe}_{2} \mathrm{Al}_{5}$ are essentially high with zero compression ratio. Generally, mechanical properties of this interfacial area remained rather consistent, indicating that a reliable joining of these two dissimilar materials had fine mechanical properties.

Similar mechanism can be used to explain the hardening of the metal near aluminum/stainless steel RL. Compared to aluminum to galvanized steel joint, microhardness of regions near RL of aluminum/stainless steel assembly is

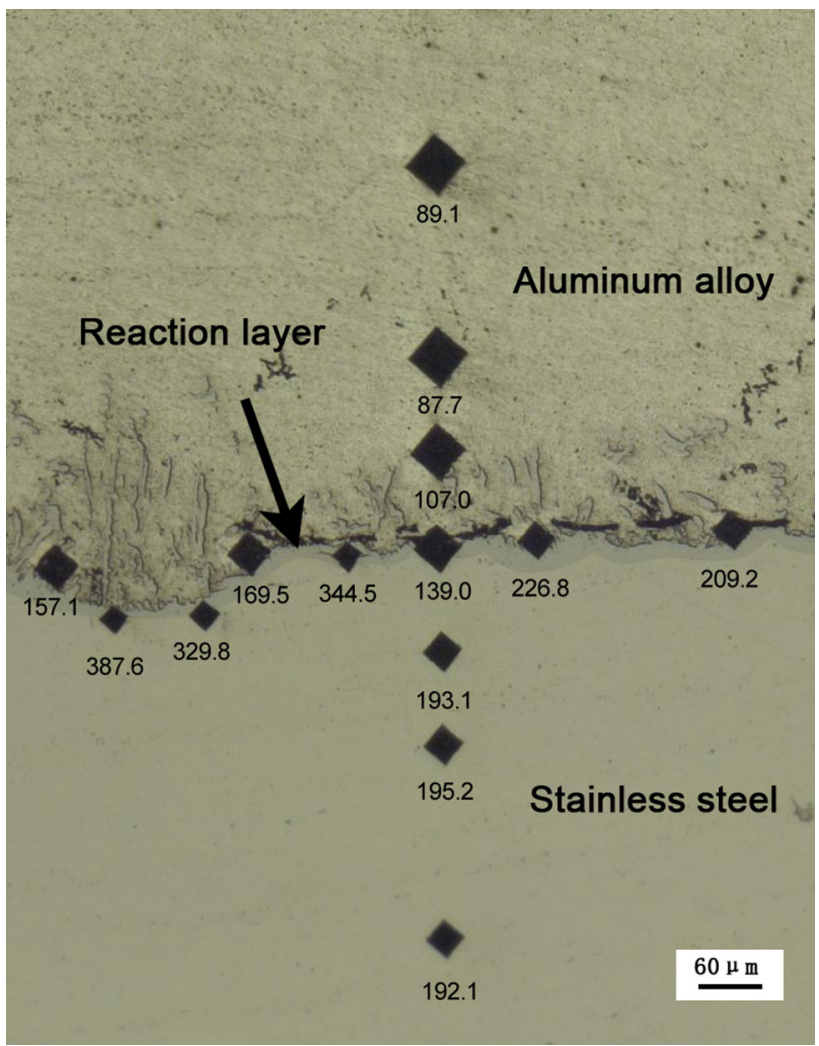

Fig. 14 Microhardness of the aluminum/stainless steel joint (Hv)

significantly higher (Fig. 14) than that of the corresponding region of the aluminum to galvanized steel assembly. The reason for this obvious discrepancy could be the formation of relatively larger amount of potential brittle Al-Fe IMCs. Correspondingly, toughness of the interfacial region might decrease. This implies that zinc and silicon are more effective in retraining the formation of brittle binary Al-Fe IMCs than chromium and nickel. Nevertheless, an effective combination of aluminum to stainless steel is achieved with certain mechanical properties.

\section{Conclusions}

With the application of bypass-current MIG arc brazingwelding method, 6061 aluminum alloy was joined to galvanized Q235 low-carbon steel using ER4043 aluminum alloy as filler metal and to SUS304 stainless steel using ER5356 aluminum alloy as filler metal. Fine and compact combination of both assembling with reliable mechanical properties was achieved.

The following major conclusions could be drawn:

- During aluminum/galvanized steel welding process, the interfacial RL was formed with a uniform and safe thickness of about 2-4 $\mu \mathrm{m}$ due to the relatively lower 
heat input. IMCs of $\mathrm{Fe}_{2} \mathrm{Al}_{5}$ and $\mathrm{FeAl}_{3}$ were formed. Silicon and zinc played predominated roles in the formation of RL. Formation of $\mathrm{Al}_{7.5} \mathrm{Fe}_{2} \mathrm{Si}$ was detected in $\mathrm{RL}$. $\mathrm{Fe}-\mathrm{Al}-\mathrm{Si}-\mathrm{Zn}$ complex system ensures a fine mechanical property of the joints.

- Compared to aluminum to galvanized steel assembly, a rather discontinuous interfacial RL with an uneven thickness ranging from 5 to $45 \mu \mathrm{m}$ was formed. In some regions, melt of steel led to the rapid growth of potential brittle IMC. Formation of $\mathrm{Al}_{4} \mathrm{CrNi}_{15}$ was detected within interfacial RL, suggesting that complex $\mathrm{Fe}-\mathrm{Al}-\mathrm{Cr}-\mathrm{Ni}$ was formed during reactive wetting which significantly strengthened the RL region.

Acknowledgements The authors are greatly indebted to the State Key Laboratory of Science and Technology on Underwater Vehicle for the support on this research and the State Key Laboratory of Advanced Welding Production Technology for the tests and analyses conducted in this research. This work was financially supported by the National Natural Science Foundation of China (No. 51005049).

\section{References}

[1] S. Lin, J. Song, C. Yang, G. Ma, Acta Metall. Sin. 45, 1211 (2009). (in Chinese)

[2] G.A. Bel'chuk, Weld Prod. 5, 14 (1961)

[3] D. Zhou, Y. Peng, S. Xu, J. Xiu, Acta Metall. Sin. 49, 959 (2013). (in Chinese)

[4] S. Wang, G. Qin, Y. Su, Acta Metall. Sin. 26, 177 (2013)

[5] R. Qiu, H. Shi, K. Zhang, Y. Tu, C. Iwamoto, S. Satonaka, Mater. Charact. 61, 684 (2010)

[6] X. Sun, E.V. Stephens, M.A. Khaleel, H. Shao, M. Kimchi, Weld. J. 83(7), 197S (2004)

[7] M. Roulin, J.W. Luster, G. Karadeniz, A. Mortensen, Weld. J. 78, 151S (1999)

[8] S. Fukumoto, H. Tsubakino, K. Okita, M. Aritoshi, T. Tomita, J. Mater. Sci. Technol. 15, 1080 (1999)
[9] G. Kawai, K. Ogawa, H. Ochi, H. Tokisue, Weld. Int. 14, 101 (2000)

[10] S. Meco, G. Pardal, S. Ganguly, S. Williams, N. McPherson, Opt. Lasers Eng. 67, 22 (2015)

[11] J. Lin, N. Ma, Y. Lei, H. Murakawa, J. Mater. Process. Technol. 213, 1303 (2013)

[12] B. Gungor, E. Kaluc, E. Taban, S. Aydin, Mater. Des. 54, 207 (2014)

[13] M. Kreimeyer, G. Sepold, in Proceedings of the International Congress on Applications of Lasers and Electro-Optics (ICALEO) (Laser Institute of America, Jacksonville, 2002)

[14] T. Murakami, K. Nakata, H. Tong, M. Ushio, ISIJ Int. 43, 1596 (2003)

[15] A. Mathieu, S. Matteï, A. Deschamps, B. Martin, D. Grevey, NDT E Int. 39, 272 (2006)

[16] R. Brockmann, K. Dickmann, C. Radscheit, E. Schubert, G. Sepold, Weld. Cut. 3, 46 (1996)

[17] M.J. Rathod, M. Kutsuna, Weld. J. 83, 16S (2004)

[18] J. Ding, F. Li, F. Qu, P. Peyre, R. Fabbro, Chin. Opt. Lett. 3, 31 (2005)

[19] Y. Miao, B. Wu, X. Xu, D. Han, Acta Metall. Sin. 27, 1038 (2014)

[20] Y. Miao, X. Xu, B. Wu, D. Han, J. Mater. Process. Technol. 214, 1590 (2014)

[21] G. Eggeler, W. Auer, H. Kaesche, Z. Met. 77, 239 (1986)

[22] R.W. Richards, R.D. Jones, P.D. Clements, H. Clarke, Int. Mater. Rev. 39, 191 (1993)

[23] J.C. Feng, P. He, H. Hackl, Solid State Phenom. 127, 43 (2007)

[24] P. Peyre, G. Sierra, F. Deschaux-Beaume, D. Stuart, G. Fras, Mater. Sci. Eng. A 444, 327 (2007)

[25] J.C. Viala, M. Peronnet, F. Barbeau, F. Bosselet, J. Bouix, Compos. Part A Appl. Sci. Manuf. 33, 1417 (2002)

[26] A. Mathieu, R. Shabadi, A. Deschamps, M. Suery, S. Matteï, D. Grevey, E. Cicalaa, Opt. Laser Technol. 39, 652 (2007)

[27] L.A. Jácome, S. Weber, A. Leitner, E. Arenholz, J. Bruckner, H. Hackl, A.R. Pyzalla, Adv. Eng. Mater. 11, 350 (2009)

[28] L. Kwang-Jin, S. Kumai, Mater. Trans. 47, 1178 (2006)

[29] H. He, Dissertation, Harbin Institution of Technology. (2014)

[30] B. Bártová, D. Vojtěch, J. Verner, A. Gemperle, V. Studnička, J. Alloys Compd. 387, 193 (2005)

[31] R. Braun, Mater. Sci. Eng. A 426, 250 (2006) 